www.jmscr.igmpublication.org

Impact Factor 5.84

Index Copernicus Value: 71.58

ISSN (e)-2347-176x ISSN (p) 2455-0450

crossref DOI: _https://dx.doi.org/10.18535/jmscr/v5i9.99

Journal Of Medical Science And Clinical Research

IGM Publication

An official Publication of IGM Publication

\title{
Congenital Hypertrophic Pyloric Stenosis At A Tertiary Care Hospital: A Surgical Experience With 30 Infants
}

\author{
Authors

\section{Dr Kawadu S. Jawade ${ }^{1}$, Dr Ansari Mohammed Abdul Muqtadir ${ }^{2}$ Dr Sarojini P. Jadhav ${ }^{3}$, Dr Ashish B Raut ${ }^{4}$}

${ }^{1}$ Senior Resident, Department Of General Surgery, Government Medical College \& Hospital Nagpur

${ }^{2}$ Associate Professor, ${ }^{3}$ Professor and Head Department of General Surgery, Government Medical College \&

Hospital Aurangabad

${ }^{4}$ Assistant Professor, Department of General Surgery, Government Medical College Akola (MS)

\begin{abstract}
Background: Congenital hypertrophic pyloric stenosis (CHPS), first described in 1888 by Harald Hirschsprung, is one of the most common cause of gastric outlet obstruction in infants. The incidence is approximately 1-4 per 1000 live births although the incidence differs in various regions and communities. It is usually seen in first born male infants and is characterized by projectile or forceful vomiting due to high pressure generated by the hypertrophied gastric muscles. No exact etiological cause is known but genetic and environmental factors are thought to be involved in etiopathegenesis. The diagnosis is usually established by ultrasonography which shows increased pyloric muscle thickness, length and diameter. Ramstedt's pyloromyotomy introduced in 1912, still remains the operative procedure of choice for management of CHPS. There is little published data regarding this condition in our setting hence we conducted this study to describe the clinical presentation, Ultrasound findings, post-operative complications and outcome in infants having CHPS.
\end{abstract}

Aims and Objectives: (1)To study the incidence and demographic characteristics of patients with CHPS. (2) To study clinical presentation like projectile vomiting, palpable lump, jaundice and dyselectrolytemia in these patients. (3) To study USG findings like pyloric canal length and wall thickness. (4) To study operative outcomes in terms of cessation of vomiting. (5) To study complication like wound gaping, persistent vomiting and aspiration.

Materials and Methods: This was a prospective cohort study comprising of 30 patients with CHPS. For this study infants presenting with non-bilious vomiting and ultrasonography features of CHPS were screened and included depending upon inclusion and exclusion criteria. All patients underwent detailed history, clinical examination, investigation and surgical treatment and they were studied for clinical features, investigation, management and morbidity and mortality patterns. The data was studied using complex statistical software.

Results: The study comprised of 50 infants with congenital hypertrophic pyloric stenosis. Out of the 30 studied cases 20 were males and 10 were females with a $M: F$ ratio of 1: 0.5. Predominantly first born children were affected $(70 \%)$ while CHPS was found in 9 cases (30\%) who were second by order of birth. The most common age of presentation was 4-8 weeks (56.7\%) followed by within 4 weeks (33.3\%) and 8-12 weeks (10\%). The analysis of children with respect to their expected weight revealed that 23 (76.6\%) infants had normal weight while 7 (23.4\%) infants had weight less than expected foe their age. As expected in CHPS all infants had non bilious vomiting. There was no patient with associated congenital anomalies. In $2(6.7 \%)$ infants there was a family history of CHPS in 1st or 2 nd degree relatives. Jaundice and constipation was present in $5(16.67 \%)$ and $3(10 \%)$ patients respectively. On clinical examination abdominal distension, palpable epigastric lump, visible peristalsis and was present in 22 (73.3\%), 14 (46.7\%) and 8 (26.7\%) infants respectively. All patients had some form of dehydration. Mild and moderate dehydration was present in 22 (73.3\%) and $8(26.7 \%)$ patients respectively. Hyponatremia and hypokalemia was present in $7(23.3 \%)$ and $9(30 \%)$ 
patients respectively. Ultrasound examination of the cases revealed that pyloric thickness was more than $4 \mathrm{~mm}$ in 24 (80\%) infants and pyloric length was more than $16 \mathrm{~mm}$ in $29(96.7 \%)$ cases. The sensitivity of ultrasound examination for diagnosis of CHPS was found to be 97\%. Isolyte P alone (50\%) or in combination with DNS (13.3\%) or RL (36.7\%) was used to correct electrolyte imbalance before surgery. In post-operative period a combination of Isolyte $P$ and Ringers lactate was used in majority (53.3\%) of the infants. Ramstedt's pyloromyotomy was done in all the infants with CHPS. In majority of the infants (79.3\%) feeding was started within 72 hours after surgery. The most common postoperative complications seen in studied cases were respiratory tract infection (20\%) followed by vomiting (16.7\%) and wound gaping (10\%). 14 (46.7\%) patients remained under follow up while 16 (53.3\%) were lost to follow up. Growth and development was found to be satisfactory in infants who were brought for regular follow up.

Conclusion: Congenital hypertrophic pyloric stenosis is most common cause of infantile gastric outlet obstruction with most common age of presentation between 4 to 8 weeks of life with a male preponderance. The condition can be diagnosed by ultrasonography and Ramstedt's pyloromyotomy is still procedure of choice for treatment of these patients.

Keywords: Congenital hypertrophic pyloric stenosis, Ultrasonography, Surgical management, Ramstedt's pyloromyotomy, outcome.

\section{Introduction}

In 1888 Hirschsprung first wrote the detailed description of congenital hypertrophic pyloric stenosis (CHPS) ${ }^{[1]}$. He believed the disease to be congenital and due to developmental defect in pyloric part of fetal stomach. The incidence of CHPS is reported to be between 1-4 cases per 1000 live births ${ }^{[2]}$. It is more common in whites than Caucasians or Asian population. First born male children are most commonly affected. The exact etiology of CHPS remains uncertain. There are various theories suggesting role of genetic, environmental and hormonal factors or a combination of them being responsible for occurrence of CHPS. Some studies have suggested that the maternal intake of macrolide antibiotics may cause CHPS in the infant ${ }^{[3]}$. The usual presentation of CHPS is non-bilious vomiting first presenting in between 4-8 weeks of life. Initially the vomiting may not be forceful but gradually the intensity of vomiting increases eventually becoming pathognomic projective vomiting. The vomiting caused by CHPS can be differentiated from vomiting due to more sinister pathologies from the fact that these are always non-bilious and despite vomiting the baby continues to suck vigorously and remains hungry [4]. Clinical examination characteristically shows presence of palpable lump in right upper quadrant in majority of the infants. The diagnosis is almost certain in the setting of an infant having nonbilious projectile vomiting, visible peristalsis and palpable pyloric lump. The Peristaltic waves may be characteristically seen moving across the child's upper abdomen from left to right before emesis $^{[5]}$. The excessive vomiting may cause electrolyte imbalance especially hypokalemia. The characteristic electrolyte abnormality seen in CHPS is hypochloremic, hypokalemic metabolic alkalosis with paradoxical aciduria. The diagnosis can be confirmed by ultrasonography which confirms the diagnosis if pyloric muscle wall thickness is $3 \mathrm{~mm}$ or more and pyloric channel length is $14 \mathrm{~mm}$ or greater $^{[6]}$. In case where ultrasonography is equivocal upper GI barium study or endoscopy may be done for the diagnosis but usually these investigations are not required and ultrasound alone can be diagnostic in majority of the cases. Once the diagnosis is confirmed the treatment is usually straight forward and consist of Ramstedt's pyloromyotomy. The usual approach for this procedure is through right upper quadrant transverse incision splitting rectus muscles and fascia $^{[7]}$. The correction of dyselectrolytemia and dehydration is crucial part of management in postoperative period. The timing of surgery depends upon the clinical status, hemodynamic stability and availability of post-operative care facilities. If the diagnosis is made early and the child is hemodynamically stable with absence of dehydration or dyselectrolytemia then the surgery could be undertaken immediately. If dehydration, hemodynamic instability or dyselectrolytemia is present then the surgery should be done only after 
correction of dehydration and dyselectrolytemia. If the baby remains hemodynamically stable the feeding can be started on the same day (6-8 hours) after surgery ${ }^{[8]}$.

The paucity of data about CHPS in our region prompted us to study this condition. The study was conducted to describe demographic characteristics, clinical presentation, ultrasound features, surgical management, post-operative complications and outcome of the patients with CHPS.

\section{Materials and Methods}

The study was conducted over a period of 2 years in Department of General Surgery at a tertiary care hospital situated in an urban area. The study was conducted after approval from institutional ethical committee. For this study infants having non bilious vomiting and ultrasonography features of CHPS were screened and included. All the cases having vomiting due to non-obstructive pathology were excluded. A detailed history was taken in all the infants. Family history with an emphasis to find out the history of similar complaints in any other first or second degree relatives was also taken. All the patients underwent detailed history, clinical examination, investigation and surgical treatment. The standard surgical treatment consisted of Ramstedt's pyloromyotomy in all the patients. In this procedure initially pyloric stenosis was located after that a longitudinal incision along relatively avascular surface of tumor through serosawas taken and scraping of pyloric muscle with blunt dissector was done finally pyloromyotomy was done [Figure 1]. The results were analyzed in terms of demographic characteristics of the patients, common clinical features, complications, surgical treatment, post-operative complications and growth and development of these infants over prolonged follow up. The data was studied using complex statistical software.

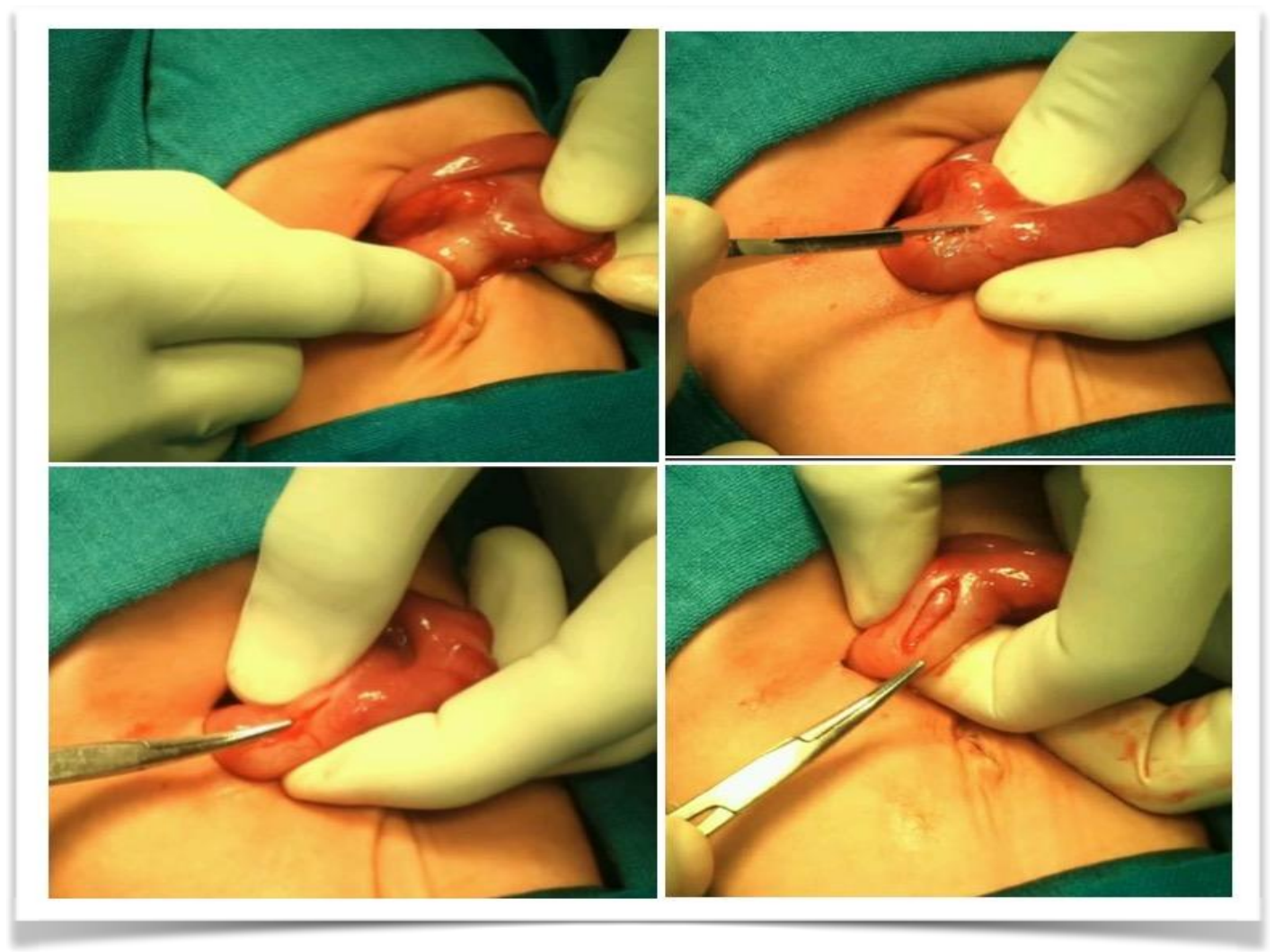

Figure 1: Various steps of surgery during Ramstedt's pyloromyotomy. 


\section{Inclusion Criteria}

1. Infants with projectile vomiting and ultrasound diagnosis of pyloric stenosis.

\section{Exclusion Criteria}

1. Infants having bilious vomiting.

2. Infants having comorbid conditions like sepsis, congenital heart disease or intestinal obstruction due to any other cause.

3. Critically ill infants.

\section{Results}

This study comprised of 50 infants with congenital hypertrophic pyloric stenosis. Out of the 30 infants enrolled in this study $20(66.7 \%)$ were males and $10(33.3 \%)$ were females with a M: F ratio of 1: 0.5.

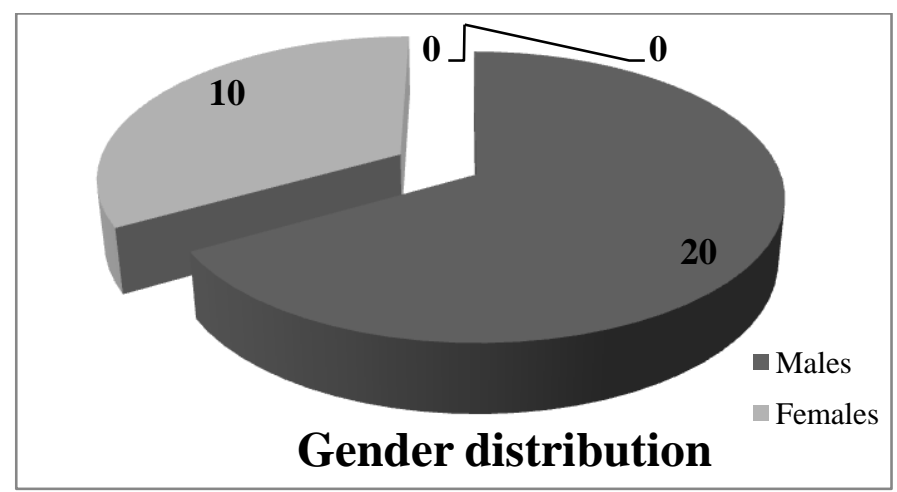

Figure 2: Gender distribution of the cases with CHPS.

The study of birth order of the affected infants with congenital hypertrophic pyloric stenosis revealed that $21(70 \%)$ of the infants were $1^{\text {st }}$ by order of birth while remaining $9(30 \%)$ infants were second by order of birth. Above 2 observations suggested that first born male children were found to be most commonly affected by CHPS.

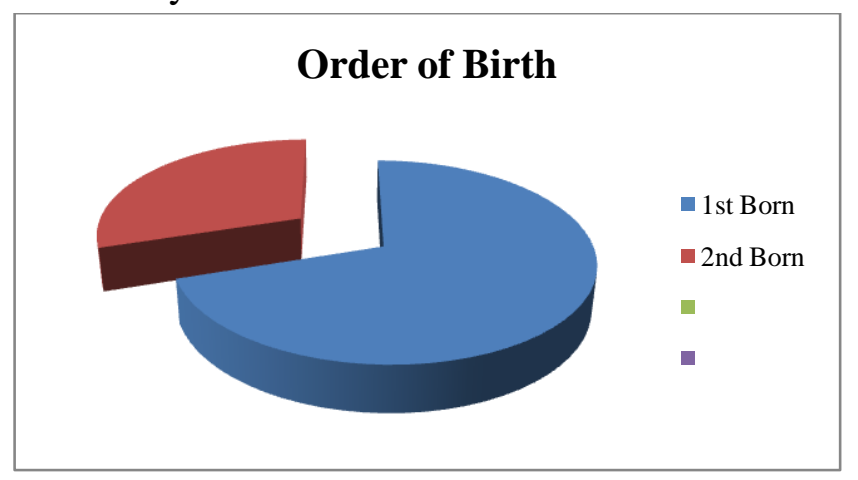

Figure 3: The order of birth of the infants having CHPS.
The analysis of age at presentation revealed that most of the infants $(56.7 \%)$ presented with nonbilious projectile vomiting in between 4-8 weeks of life. While the age at presentation was less than 4 weeks and more than 8 weeks in 10 (33.3\%) and $3(10 \%)$ patients respectively.

Table 1: Age at first presentation in studied infants.

\begin{tabular}{|lcc|}
\hline Age (Weeks) & No of Patients & Percentage \\
\hline Upto 4 weeks & 10 & $33.3 \%$ \\
\hline 4-8 weeks & 17 & $56.7 \%$ \\
\hline 8-12 weeks & 3 & $10 \%$ \\
\hline Total & 30 & $100 \%$ \\
\hline
\end{tabular}

The analysis of the weight of the infants revealed that most of the infants had a normal weight expected for the age. While $23(76.6 \%)$ infants were found to be having normal weight 7 (23.4\%) patients were found to be having weight less than expected for their age.

Table 2: Nutritional status of the studied cases

\begin{tabular}{|lcc|}
\hline Nutritional Status & No of Patients & Percentage \\
\hline Underweight & 7 & $23.4 \%$ \\
\hline Normal Weight & 17 & $76.6 \%$ \\
\hline Total & 30 & $100 \%$ \\
\hline
\end{tabular}

In most of the infants the vomiting initially was less forceful but gradually the vomiting increased in force eventually to become projectile. In all of the patients $(100 \%)$ the vomiting was non-bilious and there was no infant who presented with bilious vomiting.

Table 3: Type of vomiting in studied cases.

\begin{tabular}{|lcc|}
\hline Vomiting & No of Patients & Percentage \\
\hline Non-bilious Vomiting & 30 & $100 \%$ \\
\hline Bilious vomiting & 0 & $0 \%$ \\
\hline Total & 30 & $100 \%$ \\
\hline
\end{tabular}

In all infants a pediatric consultation was done to rule out presence of any associated congenital anomaly. However in no infant there was any associated congenital anomalies and all infants were found to be having isolated CHPS.

Table 4: Incidence of associated anomalies in studied cases

\begin{tabular}{|lccc|}
\hline Associated Anomalies & $\begin{array}{c}\text { No of } \\
\text { Patients }\end{array}$ & Percentage \\
\hline No Additional Anomalies & 30 & $100 \%$ \\
\hline $\begin{array}{l}\text { Additional Anomalies } \\
\text { Present }\end{array}$ & 0 & $0 \%$ \\
\hline Total & & \\
\hline
\end{tabular}




\section{JMSCR Vol||05||Issue||09||Page 27948-27956||September}

Since there were case reports describing increased incidence of CHPS in identical twins pointing toward the possibility of genetical factors involved in causation of CHPS a family history of all patients for presence of CHPS in infancy was taken. It was found that $2(6.7 \%)$ patients had a positive family history of CHPS in first or second degree relatives. Rest of 28 (93.3\%) patients didn't have such history.

Table 5: Family history of the studied cases

\begin{tabular}{|c|c|c|}
\hline Family History & $\begin{array}{l}\text { No of } \\
\text { Patients }\end{array}$ & Percentage \\
\hline $\begin{array}{l}\text { Patientswith family history } \\
\text { Of CHPS }\end{array}$ & 02 & $6.7 \%$ \\
\hline $\begin{array}{l}\text { Patients with no family } \\
\text { history }\end{array}$ & 28 & $93.3 \%$ \\
\hline Total & 30 & $100 \%$ \\
\hline
\end{tabular}

Constipation and jaundice was present in $3(10 \%)$ and $5(16 \%)$ patients respectively. Palpable epigastric lump is one of the characteristic findings of CHPS however a palpable epigastric lump was seen only in 14 (46.7\%) patients while $16(53.3 \%)$ patients had no palpable epigastric lump. The clinical examination in the infants with CHPS revealed that $22(73.3 \%)$ patients had abdominal distension while it was absent in 8 $(26.7 \%)$ patients. Visible peristalsis was present in $8(26.7 \%)$ patients. It was characteristically seen moving from right to left from infant's upper abdomen. The peristalsis was more marked during feeding or just before emesis.

Table 6: Signs and symptoms in the studied cases

\begin{tabular}{|lcccc|}
\hline $\begin{array}{l}\text { Signs or } \\
\text { Symptoms }\end{array}$ & Present & Percentage & Absent & Percentage \\
\hline Constipation & 3 & $10 \%$ & 27 & $90 \%$ \\
\hline Jaundice & 5 & $16.67 \%$ & 25 & $83.33 \%$ \\
\hline $\begin{array}{l}\text { Palpable } \\
\begin{array}{l}\text { Epigastric } \\
\text { lump }\end{array}\end{array}$ & 14 & $46.7 \%$ & 16 & $53.3 \%$ \\
\hline $\begin{array}{l}\text { Abdominal } \\
\text { Distension }\end{array}$ & 22 & $73.3 \%$ & 8 & $26.7 \%$ \\
\hline $\begin{array}{l}\text { Visible } \\
\text { Peristalsis }\end{array}$ & 8 & $26.7 \%$ & 22 & $73.3 \%$ \\
\hline
\end{tabular}

The dehydration was found to be present in all the infants though in $22(73.3 \%)$ cases the dehydration was only mild $8(26.7 \%)$ infants had moderate dehydration.
Table 7: Presence of dehydration in the studied cases.

\begin{tabular}{|l|c|c|}
\hline Dehydration & No Of Cases & Percentage \\
\hline Absent & 00 & 0 \\
\hline Mild & 22 & $73.3 \%$ \\
\hline Moderate & 08 & $26.7 \%$ \\
\hline Severe & 00 & 0 \\
\hline Total & 30 & $100 \%$ \\
\hline
\end{tabular}

Dyselectrolytemia was a common occurrence in infants with CHPS. The most common cause of dyselectrolytemia was frequent vomiting seen in these infants. Hyponatremia and hypernatremia was found in $7(23.3 \%) 2(6.6 \%)$ while hypokalemia was found in $9(30 \%)$ patients.

Table 8: Dyselectrolytemia in the studied cases.

\begin{tabular}{|lll|}
\hline Electrolyte Imbalance & No of Patients & Percentage \\
\hline Hyponatremia & 07 & $23.3 \%$ \\
\hline Hypernatremia & 02 & $6.6 \%$ \\
\hline Hypokalemia & 09 & $30 \%$ \\
\hline Hyperkalemia & 00 & 0 \\
\hline
\end{tabular}

Ultrasonography was done in all the patients with CHPS. Ultrasonographic finding of pyloric thickness of more than $4 \mathrm{~mm}$ was found in 24 $(80 \%)$ of the patients while pyloric length was found to be more than $16 \mathrm{~mm}$ in 29 (96.7\%) patients. Taken together these 2 ultrosongraphic parameters were found to be having sensitivity of more than $95 \%$ in the diagnosis of CHPS.

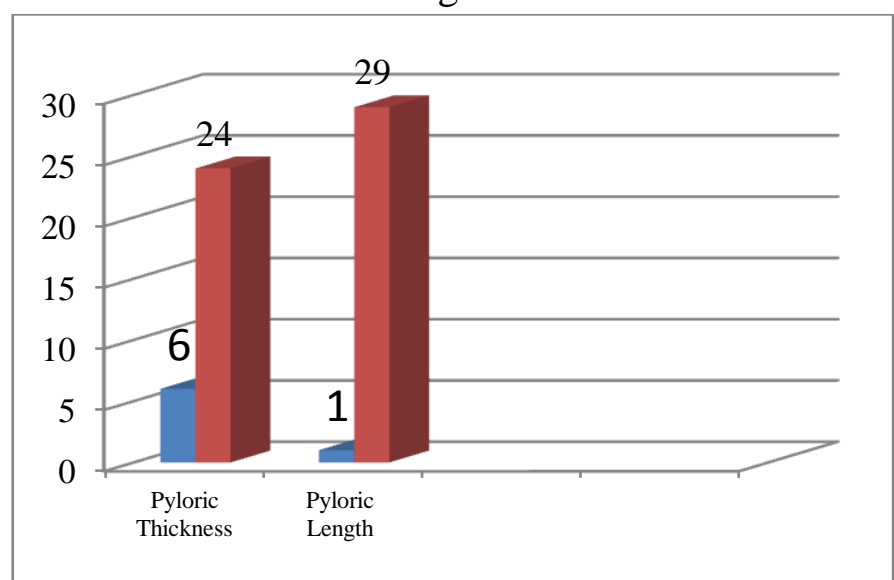

Figure 4: Ultrasound findings in patients with pyloric stenosis.

The choice of preoperative intravenous fluid used was dependent upon presence or absence of dehydration and dyselectrolytemia. In 15 (50\%) infants Isolyte $\mathrm{P}$ was used while combination of Isolyte $\mathrm{P}$ and DNS or Isolyte $\mathrm{P}$ and Ringers lactate was used in $4(13.3 \%)$ and $11(36.7 \%)$ infants respectively. While in postoperative period only 


\section{JMSCR Vol||05||Issue||09||Page 27948-27956||September}

Isolyte $\mathrm{p}$ was used in $11(36.7 \%)$. While a combination of Isolyte $\mathrm{P}$ with either DNS or RL was used in $3(10 \%)$ and $16(53.3 \%)$ patients respectively.

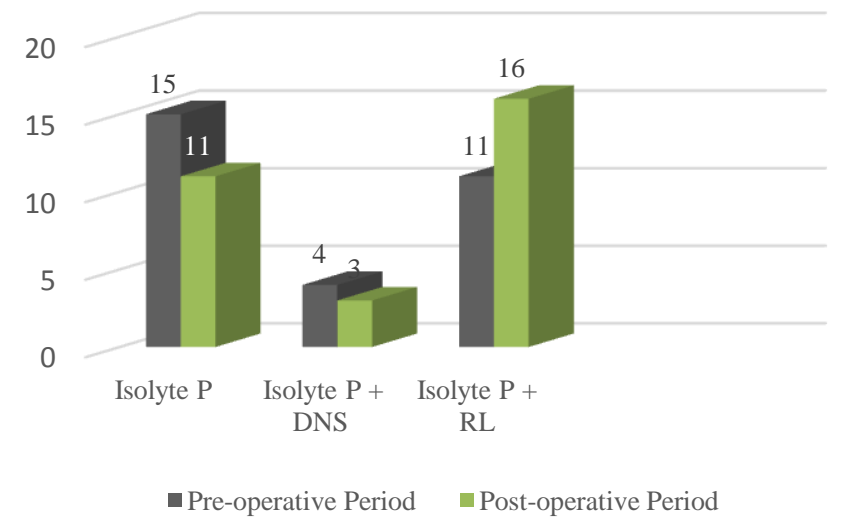

Figure 5: Fluid Management in studied cases.

Ramstedt's pyloromyotomywas done in all the infants presenting with CHPS. After the surgery feeding was started within 72 hours in 23 (76.67 $\%)$ while it was started in remaining $7(23.33 \%)$ patients after 72 hours.

Table 9: Initiation of feeding after pyloromyotomy.

\begin{tabular}{|lcc|}
\hline Feeding started & No of Patients & Percentage \\
\hline 24-48 hours & 00 & 0 \\
\hline ours & 23 & $76.67 \%$ \\
\hline$>$ 72 hours & 09 & $23.33 \%$ \\
\hline Total & 30 & $100 \%$ \\
\hline
\end{tabular}

The study of complications occurring in infants of CHPS revealed that the common complications in these patients included chest infection, vomiting and wound gaping which was seen in 6 (20\%), 5 $(16.7 \%)$ and $3(10 \%)$ patients respectively.

Table 10: Intraoperative and postoperative complication in studied infants.

\begin{tabular}{|llll|}
\hline \multirow{2}{*}{$\begin{array}{l}\text { Intraoperative } \\
\text { Local }\end{array}$} & Complications & $\begin{array}{l}\text { No of } \\
\text { Cases }\end{array}$ & Percentage \\
\cline { 2 - 4 } & Mucosal Injury & 1 & $3.3 \%$ \\
\cline { 2 - 4 } Systemic & Wound Gaping & 3 & $10 \%$ \\
\cline { 2 - 4 } & Burst Abdomen & 1 & $3.3 \%$ \\
\cline { 2 - 4 } & Vomiting & 5 & $16.7 \%$ \\
\cline { 2 - 4 } & Fever & 0 & 0 \\
\cline { 2 - 4 } & Convusions & 0 & 0 \\
\cline { 2 - 4 } Postoperative & Chest Infection & 6 & $20 \%$ \\
\cline { 2 - 4 } & Dehydration & 0 & 0 \\
& $\begin{array}{l}\text { Incomplete } \\
\text { Pyloromyotomy }\end{array}$ & 1 & $3.3 \%$ \\
\cline { 2 - 4 } & Peritonitis & 0 & 0 \\
\cline { 2 - 4 } & Septicemia & 1 & $3.3 \%$ \\
\hline
\end{tabular}

After discharge all the patients were advised follow up. 24 (46.7\%) patient remained in regular follow up while 16 (53.3\%) patients were lost to follow up. Amongst the patients who remained under follow up satisfactory growth and development was seen.

Table 11: Follow up of the studied cases

\begin{tabular}{|lcc|}
\hline Follow up & No Of Cases & Percentage \\
\hline Regular follow up & 14 & $46.7 \%$ \\
\hline Lost to follow up & 16 & $53.3 \%$ \\
\hline Total & 30 & $100 \%$ \\
\hline
\end{tabular}

\section{Discussion}

Since Harald Hirschsprung first described CHPS in 1881 it has been one of the most common cause of gastric outlet obstruction and surgical cause of vomiting. It most commonly affects first born male children. The reason for male preponderance is not well understood though authors like Carter and Evans defined the disease as a "paradigm for the multifactorial, sex-modified threshold model of inheritance. [9]" In our studies first born and male infants were affected more commonly than female infants and infants who were 2 nd by order of birth. These findings were in conformity with the studies conducted by A C. Paul et $\mathrm{al}^{[10]}$, Salman Al-Ghazwany et $\mathrm{al}^{[11]}$ and Amier. A. Ejrish et al ${ }^{[12]}$.

The age of presentation is usually from 4 to 8 weeks of life. In our study most of the infants presented with vomiting and dehydration between 4-8 weeks of life followed by within 4 weeks and 8-12 weeks. None of our patients presented after the age of 12 weeks of life. These findings were similar to the studies conducted by Kumar A et al ${ }^{[13]}$ and Phillipo L Chalya et al ${ }^{[14]}$.

One of the interesting aspect of the study of CHPS is the role of genetic factors in causation of CHPS. There are many studies which have shown the incidence of CHPS to be more in monozygotic twins. Higher concordance in monozygotic twins may points towards presence of some genetic component in the causation of CHPS though no definite locus has been yet identified. In an interesting study Mitchell LE et al concluded that the familial recurrence pattern among monozy- 
gotic twins and more remote relatives of CHPS probands was found to be inconsistent with generalized single major locus inheritance and the familial recurrence pattern of CHPS, however, was found to be compatible with multifactorial threshold inheritance or the effects of multiple interacting loci. In any case no single causative factor could be identified and it has been widely reported that the cause of CHPS may be multifactorial including environmental and genetic factors ${ }^{[15]}$.

Although in our study no patient was found to be having associated congenital anomalies many authors have reported a higher incidence of various anomalies like abnormalities of the upper urinary tract, inguinal hernia, undescended testes, oesophageal atresia and hypospadias in infants with CHPS ${ }^{[16]}$.

The clinical features of CHPS include forceful or projectile non-bilious vomiting, visible peristalsis and a palpable lump in right upper quadrant. In our study all the infants with CHPS had projectile non-bilious vomiting and visible peristalsis and palpable lump was found in $27 \%$ and $46.7 \%$ infants respectively. These findings were similar to the studies conducted by JD Ranells et al ${ }^{[17]}$.

In our study the incidence of constipation, jaundice and dehydration was seen in 9\%, 16\% and $100 \%$ patients. Hyponatremia, hypernatremia and hypokalemia was seen in $23.3 \%, 6.6 \%$ and $30 \%$ patients respectively. Similar findings were reported by NMadu PT, Spicer RD and JG Tutay $[18,19,20]$

$\mathrm{X}$-Ray is not a sensitive or specific investigation for CHPS buy may show distension of abdomen in some cases. In our study 7 patients had shown e/o abdominal distension on erect X-Ray abdomen. The ultrasonography of abdomen is a sensitive and specific test for diagnosis of CHPS. In this study ultrasonographic finding of pyloric thickness of more than $4 \mathrm{~mm}$ was seen in $24(80 \%)$ of the patients while pyloric length was found to be more than $16 \mathrm{~mm}$ in $29(96.7 \%)$ patients. The sensitivity of ultrasound for the diagnosis of CPHS was found to be $97 \%$. These findings were similar to the findings of the authors like Meena Said et al, M Hussain et al and Sílvia Costa Dias et al ${ }^{[21,22,23]}$.

In our study the most common IV fluid used in pre-operative period was Isolyte $\mathrm{P}$ which was used in 50\% patients while rest of the infants received a combination of Isolyte-p and either Ringer's lactate or DNS. This management was similar to Shwartz who used $5 \%$ dextrose with $1 / 2$ normal saline and Hisham Nazerwho used Ringer's lactate to correct dehydration and metabolic disturbances ${ }^{[24,25]}$.

In our study all patients of CHPS underwent classical Ramstedt's pyloromyotomy, transverse incision in upper quadrant was taken in all the patients and they were managed postoperatively by IV Isolyte $\mathrm{p}$ and lactated ringer with prophylactic antibiotics. Feeding was started within 72 hours in $23(76.67 \%)$ patients while it was started in remaining $7(23.33 \%)$ patients after 72 hours. Similar post-operative feeding pattern were seen in study conducted by Carpenter RO, G Aspelund and Georgeson $\mathrm{KE}^{[26,27,28]}$. Vomiting and chest infection were the most common complications seen postoperatively. Similar complication rates were found in study done by Solowiejczyk M et al and Gibbs MK et al ${ }^{[29,30]}$.

\section{Conclusion}

Congenital hypertrophic pyloric stenosis is the most common cause of pediatric gastric outlet obstruction presenting usually between 4 to 8 weeks of age.First born male child is more likely to be affected than others. The hallmark clinical picture is infant presenting with Projectile non bilious vomiting with local epigastric distension, palpable pyloric tumor and visible peristalsis. Most of the patients with CHPS are mildly dehydrated and may have dyselectrolytemia. Ultrasound is the best investigation to diagnose the condition and Ramstedt's open pyloromyotomy is still procedure of choice. Chest infection is most common post-operative complication.

Conflict Of Interest: None 


\section{References}

1. Hirschsprung $\mathrm{H}$. Falle von angeborener pyloric stenose. Jb Kinderheik. 1888;27:61

2. Ohshiro K, Puri P. Pathogenesis of infantile hypertrophic pyloric stenosis: recent progress. PediatrSurg Int. 1998 Apr;13(4):243-52.

3. Feng Z, Nie Y, Zhang $\mathrm{Y}$, et al. The Clinical Features of Infantile Hypertrophic Pyloric Stenosis in Chinese Han Population: Analysis from 1998 to 2010. Huang L-M, ed. PLoS ONE. 2014;9(2): e88925.

4. Schechter R, Torfs CP, Bateson TF. The epidemiology of infantile hypertrophic pyloric stenosis. PaediatrPerinatEpidemiol. 1997 Oct;11(4):407-27.

5. Chalya PL, Manyama M, Kayange NM, Mabula JB, Massenga A. Infantile hypertrophic pyloric stenosis at a tertiary care hospital in Tanzania: a surgical experience with 102 patients over a 5-year period. BMC Research Notes. 2015;8:690.

6. Hussain M. Sonographic Diagnosis of Infantile Hypertrophic Pyloric stenosisUse of Simultaneous Grey-scale \&Colour Doppler Examination. International Journal of Health Sciences. 2008;2(2):134-140.

7. Maxwell-Armstrong CA, Cheng M, Reynolds JR, Holliday HW. Surgical management of infantile hypertrophic pyloric stenosis--can it be performed by general surgeons? Annals of The Royal College of Surgeons of England. 2000;82(5):341-343.

8. Hulka F, Harrison MW, Campbell TJ, Campbell JR. Complications of pyloromyotomy for infantile hypertrophic pyloric stenosis. Am J Surg. 1997 May;173(5):450-2.

9. Carter $\mathrm{CO}$, Evans KA, Inheritance of congenital pyloric stenosis.J Med Genet. 1969 Sep; 6(3):233-54.

10. A.C Paul, MJ Alam IHPS Faridpur Med Coll.J.2011;6 (1); 01-04 .
11. Salman Al Ghawzwany , Infantile hypertrophic pyloric stenosis, Annals pediatric surgery 2012 vol 8 no 2 ; 39-42

12. Amier A Ejrish IHPS, MEDICAL JOURNAL of BABYLON ; 2014; Vol 6 (3) 596-599.

13. Kumar A et al , study of clinical, biochemical evaluation and outcomes in hypertrophic pyloric stenosis, Int $\mathrm{J}$ ContempPediatr. 2016 may ; 3 (2) 473-476

14. Phillipo L Chalya, Mange Manyama, Neema M. Kayange , Infantile pyloric stenosis BMC Res Notes 2015 ; 8: 690 Mitchell LE, Risch N. The genetics of infantile hypertrophic pyloric stenosis A reanalysis. Am J Dis Child. 1993 Nov;147(11):1203-11.

15. Atwell JD, Levick P. Congenital hypertrophic pyloric stenosis and associated anomalies in the genitourinary tract. J Pediatr Surg. 1981 Dec;16(6):102935.

16. Ranells JD, Carver JD, Kirby RS. Infantile hypertrophic pyloric stenosis: epidemicology, genetics, and clinical update. AdvPediatr. 2011;58(1):195-206.

17. Nmadu PT. Alterations in serum electrolytes in congenital hypertrophic pyloric stenosis: a study in Nigerian children. Ann Trop Paediatr 1992; 12:169.

18. Spicer RD. Infantile hypertrophic pyloric stenosis: a review. Br J Surg 1982; 69:128.

19. Tutay GJ, Capraro G, Spirko B, Garb J, Smithline H. Electrolyte profile ofpediatric patients with hypertrophic pyloric stenosis. PediatrEmerg Care. 2013 Apr;29(4):465-8.

20. Said M, Shaul DB, Fujimoto M, Radner G, Sydorak RM, Applebaum H. Ultrasound Measurements in Hypertrophic Pyloric Stenosis: Don't Let the Numbers Fool You. The Permanente Journal. 2012;16(3):25-27.

21. Hussain M. Sonographic Diagnosis of Infantile Hypertrophic Pyloric stenosis- 
Use of Simultaneous Grey-scale \&Colour Doppler Examination. International Journal of Health Sciences. 2008;2(2):134140.

22. Costa Dias S, Swinson S, Torrão H, et al. Hypertrophic pyloric stenosis: tips and tricks for ultrasound diagnosis. Insights into Imaging. 2012;3(3):247-250.

23. Schwartz MZHypertrophic pyloric stenosis in paediatric surgery. 1111-17.

24. HishamNazer Allan C. Terminantsog good outcome in pyloric stenosis. JPS 2006:42(3):86-8.

25. Carpenter RO, Schaffer RL, Maeso CE, Sasan F, Nuchtern JG, Jaksic T, Harber FJ, Wesson DE, Brandt ML. Postoperative ad lib feeding for hypertrophic pyloric stenosis. J Pediatr Surg. 1999 Jun;34(6):959-61.

26. Aspelund G, Langer JC. Current management of hypertrophic pyloric stenosis. SeminPediatr Surg. 2007 Feb; 16(1):27-33. Review. PubMed PMID: 17210480 .

27. Georgeson KE, Corbin TJ, Griffen JW, Breaux CW Jr. An analysis of feeding regimens after pyloromyotomy for hypertrophic pyloric stenosis. J Pediatr Surg. 1993 Nov;28(11):1478-80

28. Solowiejczyk M, Holtzman M, Michowitz M. Congenital hypertrophic pyloric stenosis: a long-term follow-up of 41 cases. Am Surg. 1980 Oct;46(10):567-71.

29. Gibbs MK, Van Herrden JA, Lynn HB. Congenital hypertrophic pyloric stenosis. Surgical experience. Mayo Clin Proc. 1975 Jun;50(6):312-6. 